SUPPORTING INFORMATION

\title{
Nickel-Sulfonate Mode of Substrate Binding for Forward and Reverse Reactions of Methyl-SCoM Reductase Suggest a Radical Mechanism Involving Long Range Electron Transfer
}

\author{
Anjali Patwardhan ${ }^{\ddagger}$ Ritimukta Sarangi ${ }^{\S}$, Bojana Ginovska $^{\$}$, Simone Raugei ${ }^{\$}$, and Stephen W. \\ Ragsdale ${ }^{\ddagger *}$ \\ From the $\neq$ Department of Biological Chemistry, University of Michigan, Ann Arbor, Michigan 48103, and §Stanford \\ Synchrotron Radiation Lightsource, SLAC National Accelerator Laboratory, Menlo Park, California 94025 and \\ \$Pacific Northwest National Laboratory, Richland, WA 99354
}

Keywords: nickel; methane; long-range electron transfer; radical transfer; X-ray absorption; computational chemistry; enzyme mechanisms; enzyme kinetics.

* To whom correspondence should be addressed: Department of Biological, Chemistry, University of Michigan Medical School, 1150 W. Medical Center Dr., 5301 MSRB III, Ann Arbor, MI USA, 481090606, Tel: 734-615-4621; Fax: 734-763-4581; E-mail: sragsdal@umich.edu 

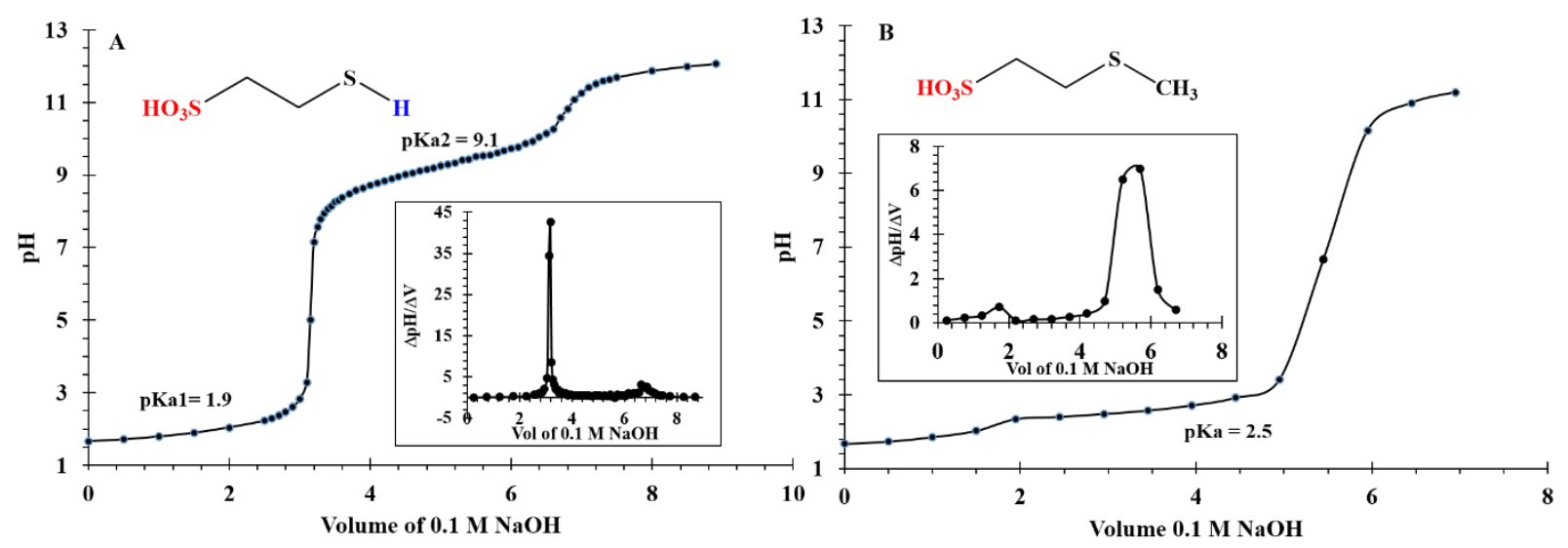

Figure S1: pH titration curves for MCR substrates. A: CoMSH and B: methyl-SCoM. Insets correspond to the derivative plot with peak corresponding to equivalence point $\mathrm{pH} . \mathrm{pH}$ measured at half equivalence point is the $\mathrm{p} K \mathrm{a}$. 


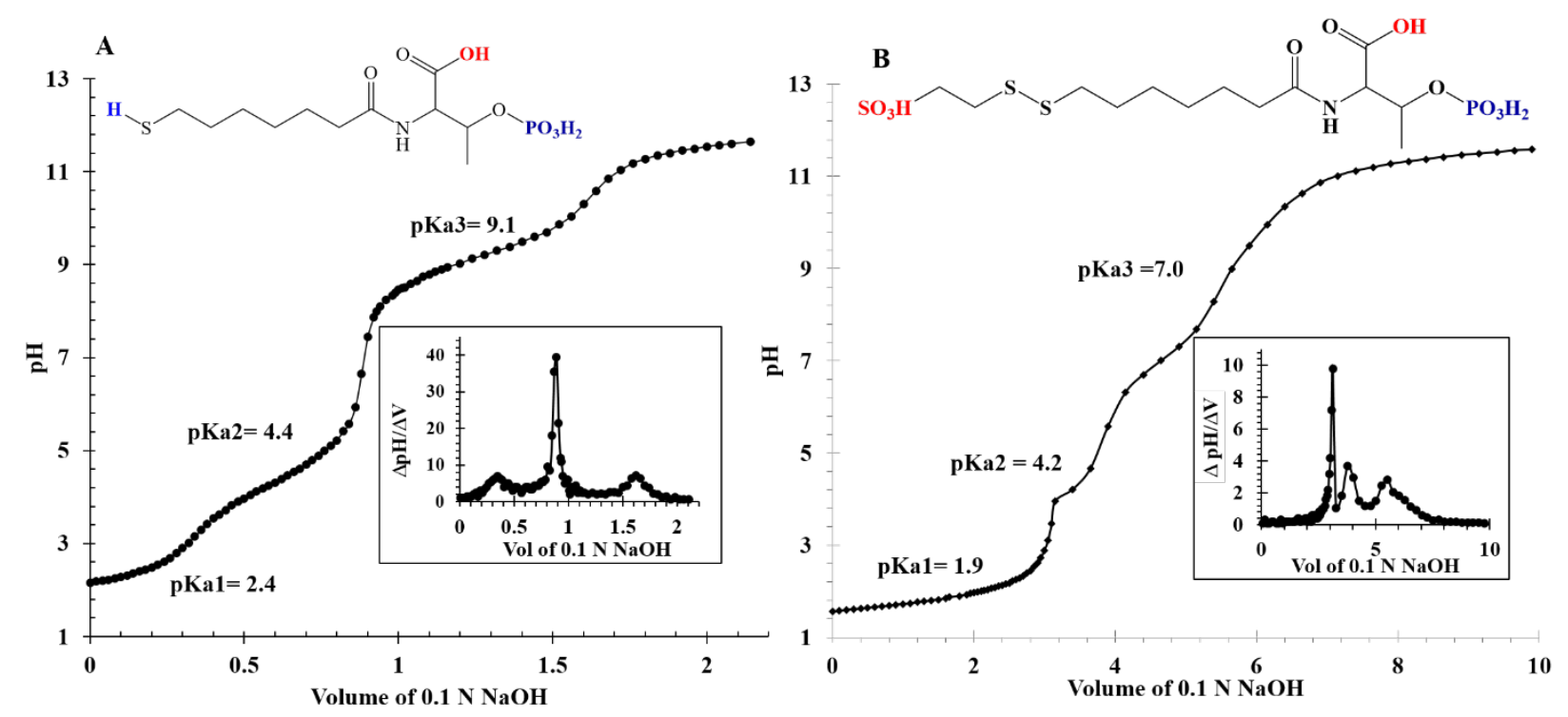

Figure S2. pH titrations of MCR substrates. (A) CoBSH and (B) CoMSSCoB. The insets are the plots of the ratio of change in $\mathrm{pH}$ to the change in volume $(\Delta \mathrm{pH} / \Delta \mathrm{V})$ vs $\mathrm{Vol}(\mathrm{V})$ with the peak corresponding to the equivalence point volume. The $\mathrm{pH}$ measured at half equivalence point equals the $\mathrm{p} K \mathrm{a}$ of the group being titrated. 
A

${ }^{1}$ H-NMR CoBSH

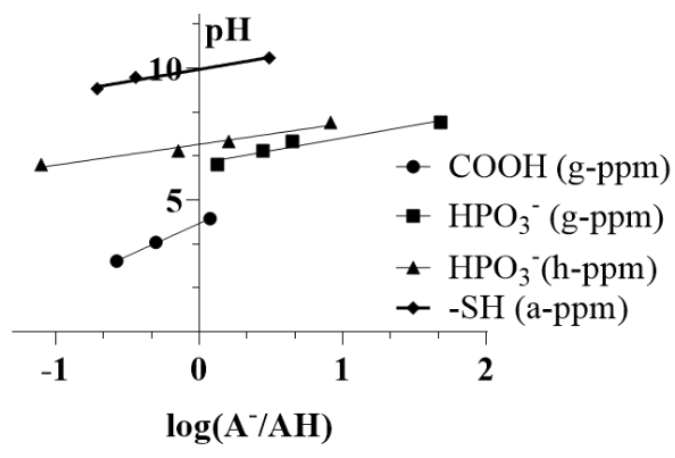

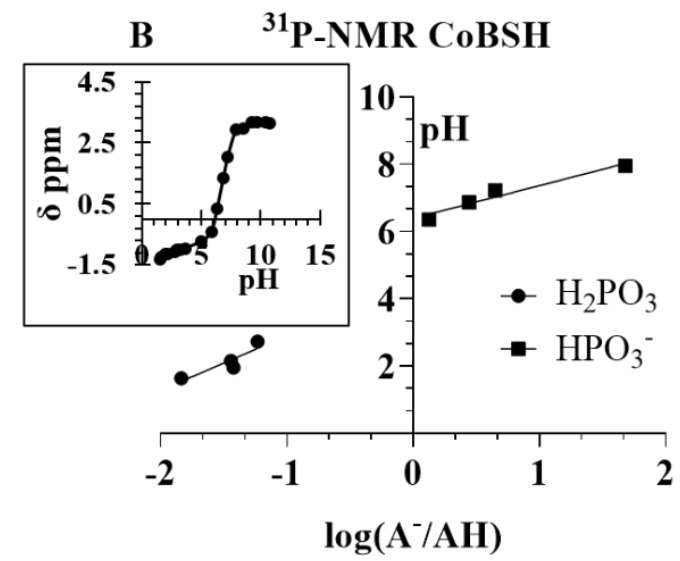

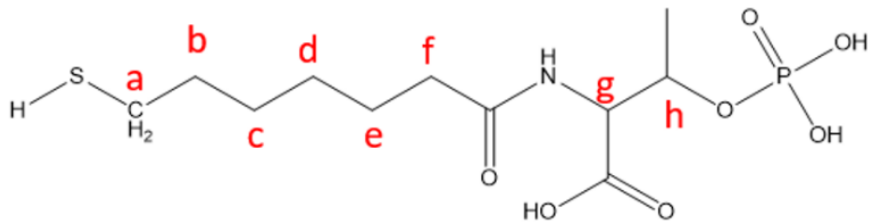

Figure S3. Determination of pKa s of CoBSH using ${ }^{1} \mathrm{H}-\mathrm{NMR}$ and ${ }^{31} \mathrm{P}-\mathrm{NMR}$ by monitoring changes in chemical shifts with pH. (A) Linear plot of $\mathrm{pH}$ vs $\log (\mathrm{A} / \mathrm{AH})$ (ratio of deprotonated to protonated species) results in a Y-intercept that gives the $\mathrm{pKa}$ of the titrated group. Changes in $\delta \mathrm{ppm}$ of the $\mathrm{Hg}$ proton (sensitive to deprotonation of $-\mathrm{COOH}$ ), $\mathrm{Hh}$ proton (sensitive to $\mathrm{H}_{2} \mathrm{PO}_{3}$ ionization) and Ha proton (sensitive to thiol group deprotonation) due to changes in $\mathrm{pH}$ were used to determine the $\mathrm{pKa}$ of the ionizable group. (B) $\mathrm{pKa}$ values of phosphate group of $\mathrm{CoBSH}$ as determined by ${ }^{31} \mathrm{P}-\mathrm{NMR}$ measurements. $\mathrm{Y}$ intercept for the linear plot of $\log (\mathrm{A} / \mathrm{AH}) \mathrm{vs} \mathrm{pH}$ is the $\mathrm{pKa}$ for the corresponding deprotonation. Concentration of $\mathrm{A}^{-}$and $\mathrm{AH}$ is calculated from concentration and volume of $0.1 \mathrm{M}$ $\mathrm{NaOH}$ added. ${ }^{67}$ 
A

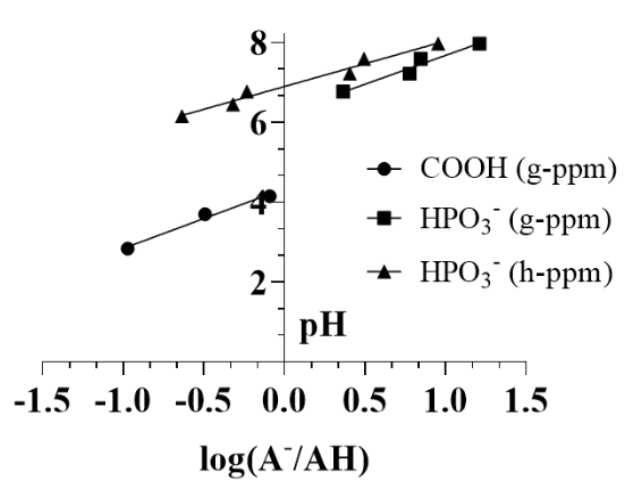

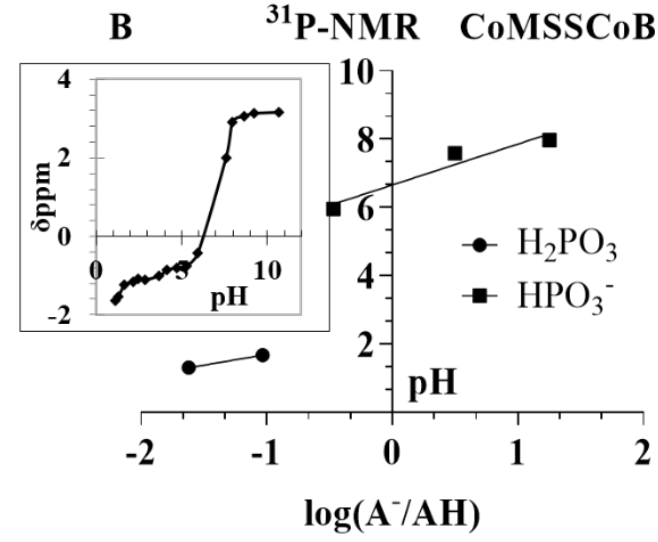

$\log \left(\mathrm{A}^{-} / \mathrm{AH}\right)$<smiles>[X]C(CSSCCCCCCC(=O)NC(C(=O)O)C(C)OP(=O)(O)O)S(=O)(=O)O</smiles>

Figure S4. Determination of pKas of CoMSSCoB using ${ }^{1} \mathrm{H}-\mathrm{NMR}$ and ${ }^{31} \mathrm{P}-\mathrm{NMR}$ by monitoring changes in chemical shifts with $\mathrm{pH}$. (A) Linear plot of $\mathrm{pH}$ vs $\log \left(\mathrm{A}^{-} / \mathrm{AH}\right)(\mathrm{ratio}$ of deprotonated to protonated species) results in a Y-intercept that gives the $\mathrm{pKa}$ of the titrated group. Changes in $\delta \mathrm{ppm}$ of the $\mathrm{Hg}$ proton (sensitive to deprotonation of $-\mathrm{COOH}$ ), and $\mathrm{Hh}$-proton (sensitive to $\mathrm{H}_{2} \mathrm{PO}_{3}$ ionization) due to changes in $\mathrm{pH}$ are used to determine the $\mathrm{pKa}$ of the ionizable group. The $\mathrm{Hk}$ proton chemical shift remained unchanged throughout the experiment suggesting it was deprotonated at $\mathrm{pH} 1$. (B) $\mathrm{pKa}$ values of phosphate group of CoBSH as determined by ${ }^{31} \mathrm{P}-\mathrm{NMR}$ measurements. Y intercept for the linear plot of $\log \left(\mathrm{A}^{-} / \mathrm{AH}\right)$ vs $\mathrm{pH}$ is the $\mathrm{pKa}$ for the corresponding deprotonation. Concentration of $\mathrm{A}^{-}$and $\mathrm{AH}$ are calculated from the concentration and volume of $0.1 \mathrm{M}$ $\mathrm{NaOH}$ added. ${ }^{67}$ 


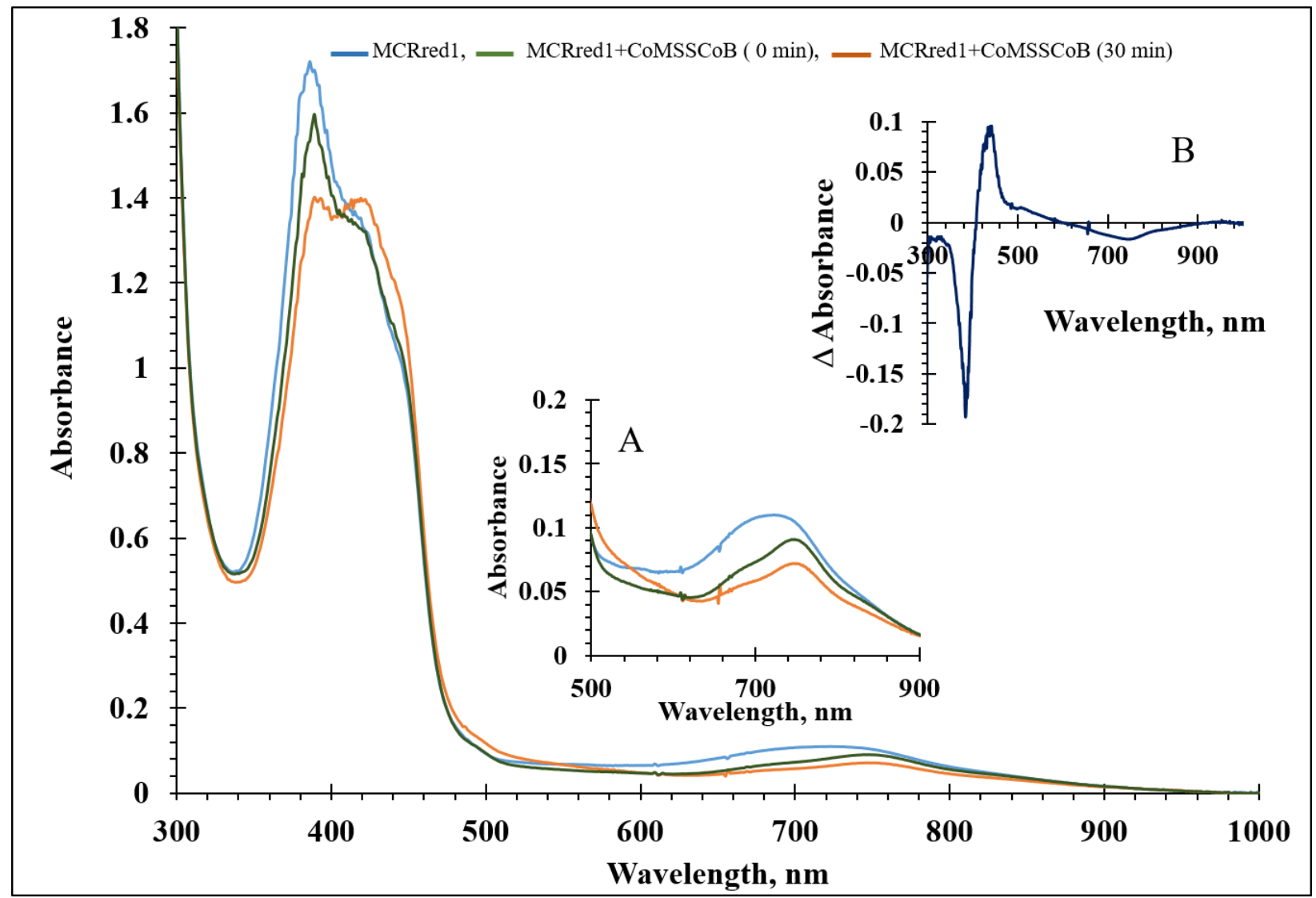

Figure S5. UV-visible and NIR spectra of reaction of MCRred1 with CoMSSCoB. Reaction of $50 \mu \mathrm{M}$ MCRred $1+5 \mathrm{mM}$ CoMSSCoB monitored from 300nm to $1000 \mathrm{~nm}$ to capture the changes in redox state of MCRred1 [Ni(I) @ $385 \mathrm{~nm} \rightarrow \mathrm{Ni}(\mathrm{II}) / \mathrm{Ni}(\mathrm{III}) @ 420 / 445(\mathrm{sh}) \mathrm{nm}$ ] over 30 minutes. Inset A. NIR changes highlight the shift in $\lambda \max$ from $(-) 700 \mathrm{~nm} \rightarrow(-) 768 \mathrm{~nm}$ on addition of CoMSSCoB and its subsequent decay over time (-). Inset B. Difference spectra of the spectra at $30 \mathrm{~min}$ and $0 \mathrm{~min}$ highlights the increase in absorbance at $445 \mathrm{~nm}$ associated with a decrease in absorbance at $768 \mathrm{~nm}$. 


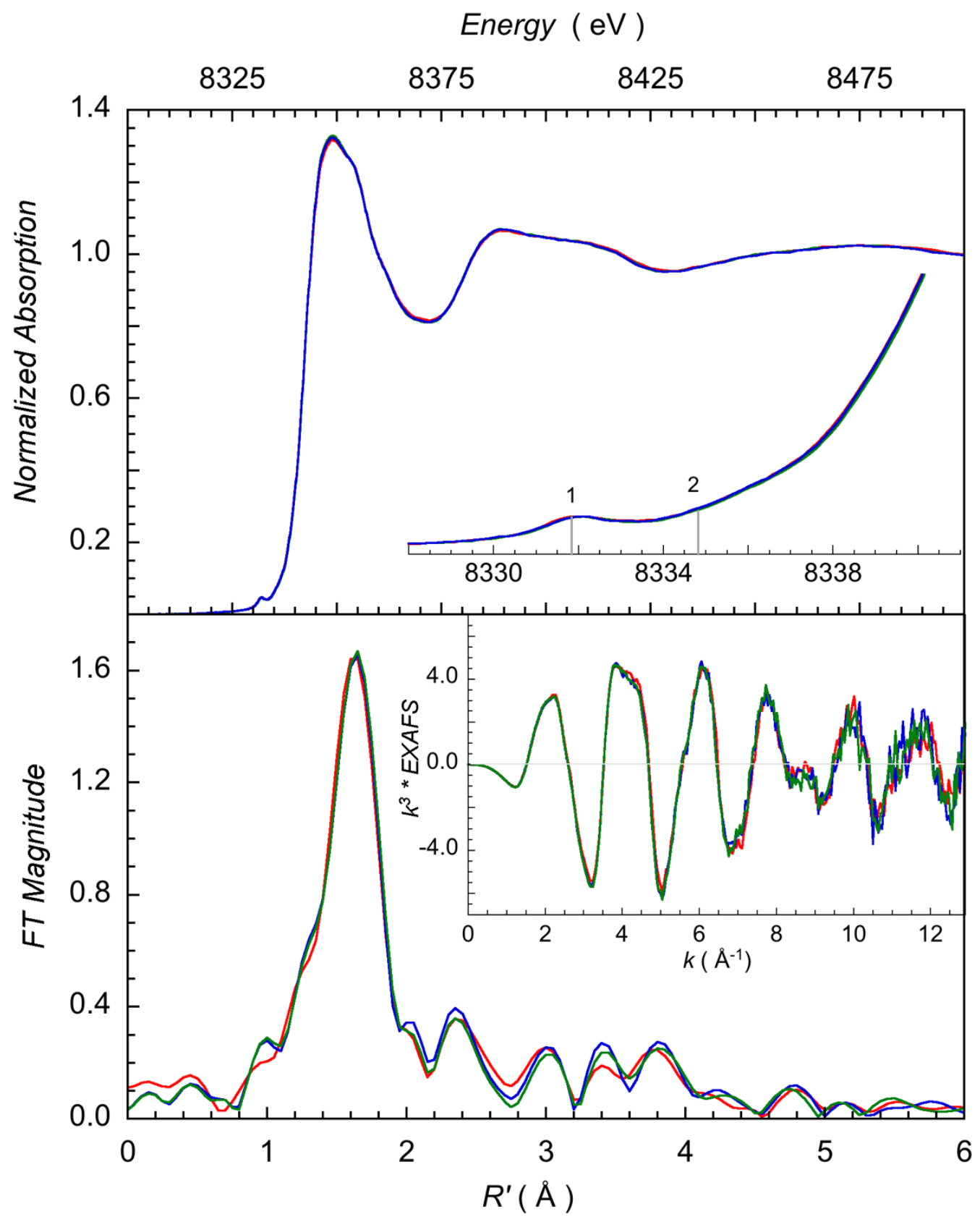

Figure S6. XAS spectra of MCRred1c-silent with substrates shows no changes. Top row: A comparison of the normalized $\mathrm{Ni} \mathrm{K}$-edge XAS data for $\mathrm{MCR}_{\text {Red ISilent }}(-), \mathrm{MCR}_{\text {Red ISilent }}+$ $\mathrm{CoMCoB}(-)$ and $\mathrm{MCR}_{\text {Redisilent }}+\mathrm{CoMCoB} 6(-)$. The inset in each plot shows the expanded preedge region. The markers at ' $\sim 8332 \mathrm{eV}$ ' and ' $\sim 8334.5 \mathrm{eV}$ ' represent the $1 \mathrm{~s} \rightarrow 3 \mathrm{~d}$ transition and the back-bonding transition involving interactions between the F430 ring and the $\mathrm{Ni}$ center, respectively. Bottom row: A comparison of the Ni K-edge EXAFS data (inset) and their corresponding Fourier Transforms. 